\title{
A computationally efficient approach for watershed scale spatial
}

\section{optimization}

\author{
Cibin R. ${ }^{1}$ and Chaubey, I. ${ }^{2 *}$ \\ ${ }^{1}$ Department of Agricultural and Biological Engineering, Purdue University, West \\ Lafayette, IN, USA - 47907. \\ ${ }^{2}$ Department of Earth, Atmospheric, and Planetary Sciences; Department of Agricultural \\ and Biological Engineering, Purdue University, West Lafayette, IN, USA - 47907. \\ *Corresponding Author. Email: ichaubey@ purdue.edu; Phone (001) 7654943258
}

\begin{abstract}
A multi-level spatial optimization (MLSOPT) approach is developed for solving complex watershed scale optimization problems. The method works at two levels: a watershed is divided into small sub-watersheds and optimum solutions for each subwatershed are identified individually. Subsequently sub-watershed optimum solutions are used for watershed scale optimization. The approach is tested with complex spatial optimization case studies designed to maximize crop residue (corn stover) harvest with minimum environmental impacts in a $2000 \mathrm{~km}^{2}$ watershed. Results from case studies indicated that the MLSOPT approach is robust in convergence and computationally efficient compared to the traditional single-level optimization frameworks. The MLSOPT was 20 times computationally efficient in solving source area based optimization problem while it was 3 times computationally efficient for watershed outlet based optimization problem compared to a corresponding single-level optimizations. The MLSOPT optimization approach can be used in solving complex watershed scale spatial optimization problems effectively.
\end{abstract}

Key Words: watershed scale optimization, multi-level optimization, residue removal, biofuel production, SWAT model. 


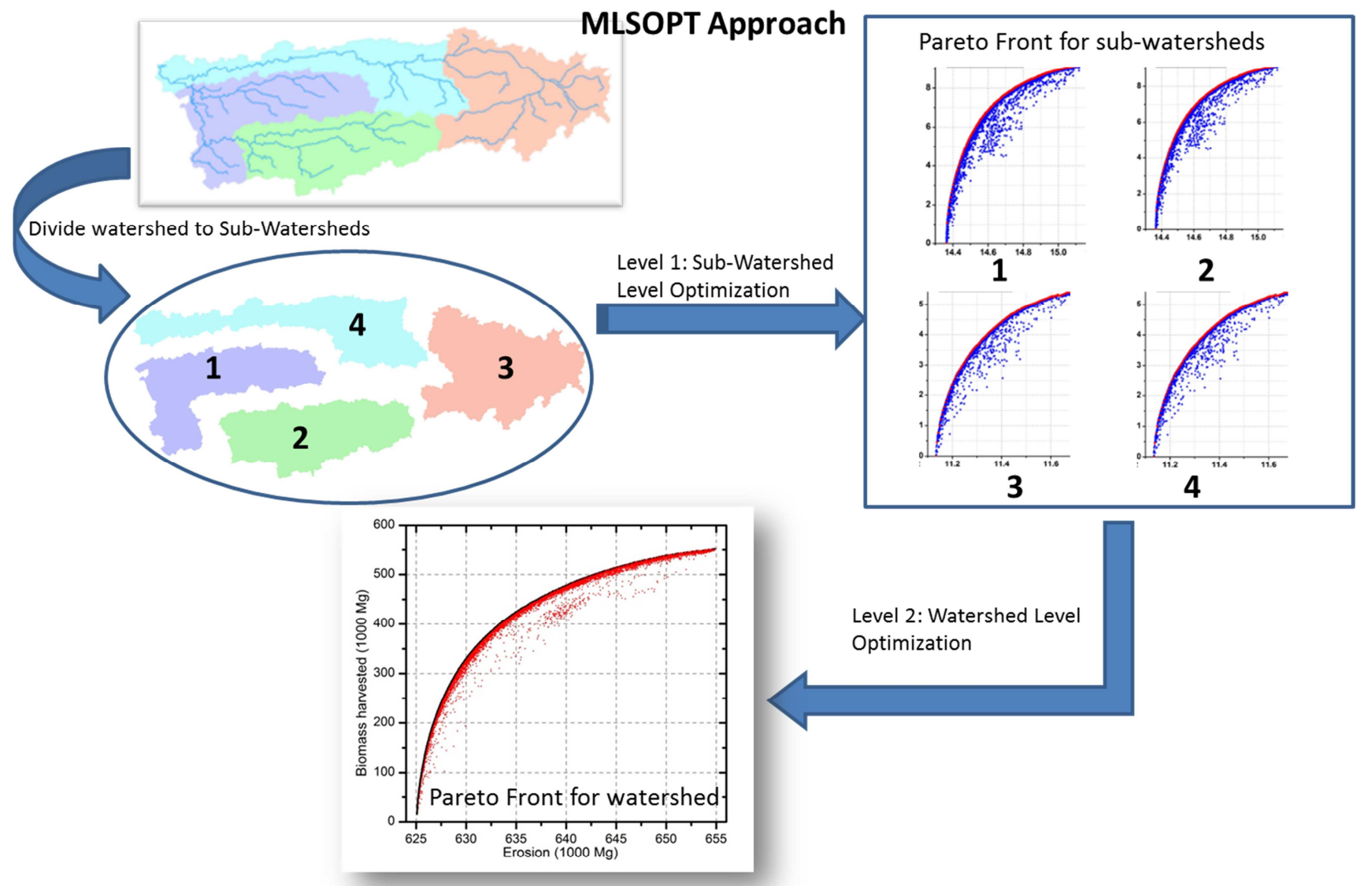

Graphical abstract 


\section{Introduction}

Spatial optimization of land use and conservation practices under various objective functions/constraints can help sustainably manage limited resources available in a watershed. Spatial optimization of agricultural best management practices (BMP) has been done by many researchers to identify the best locations and practices within a watershed with minimum implementation cost and maximum economic and/or environmental returns (Srivastava et al., 2002; Bekele and Nicklow, 2005; Arabi et al., 2006; Maringanti et al., 2011; Lautenbach et al., 2013; among many others). However, most of these studies were limited to research problems with minimum practical implementation. In addition, most were conducted in relatively smaller watersheds or in simplified model representation where the search space for optimal solutions is relatively smaller resulting in efficient implementation of the optimization algorithms.

The most popular method of spatial optimization is dynamic linking of a watershed simulation model with an optimization algorithm (Srivastava et al., 2002; Bekele and Nicklow, 2005; Arabi et al., 2006; Lautenbach et al., 2013; Kalcic et al., 2014; among many others), wherein the simulation model outputs are used to estimate the objective functions for the optimization algorithm. A major limitation of this approach is the computational cost associated with model dynamic simulations. Generally, spatial optimization problems require tens of thousands of model simulations which can take several days or even weeks to complete (Arabi et al., 2006). Parallel computing could be one solution to reduce the computational time (Rouholahnejad et al., 2012; Wu et al., 2013; Zhang et al., 2013; Yalew et al., 2013; Joseph and Guilluame, 2013), but often parallel computing facilities available to model users are limited. Another solution would be to select computationally efficient watershed simulation models for objective function evaluations. However, spatial optimization requires distributed-parameter watershed models to simulate spatial variability of hydrologic/water quality processes and such models are generally computationally complex. Computational costs associated with use of complex models have resulted in innovative approaches of using surrogate models (Sreekant and Datta, 2011) or lookup tables (Maringanti et al., 2009, 2011; Gitau et al., 
2004) instead of direct usage of simulation model in optimization framework. In such applications a computationally simple surrogate model or look-up table (also called pseudo-simulation models, Sudheer et al., 2011) is created using a few scenarios simulated from watershed models and these pseudo simulation models are linked with an optimization algorithm. This approach makes the optimization computationally efficient by considerably reducing the time to reach optimal solution (Maringanti et al., 2009; Sreekant and Datta, 2011). However, a major limitation of this approach is that surrogate models can induce another level of uncertainty to the optimization results (Sreekant and Datta, 2011) as they are much simpler representation of the behavior of complex natural systems.

Selection of an efficient optimization algorithm is also critical in spatial optimization for efficient solution convergence. Evolutionary optimization methods such as genetic algorithms (Holland, 1975; Goldberg, 1989) are popular in spatial optimization (Chatterjee, 1997; Srivastava et al., 2002; Veith et al., 2003; Gitau et al., 2004; Arabi et al., 2006; Maringanti et al., 2009, 2011; Lautenbach et al., 2013; among many others). Even efficient optimization algorithms may fail to converge when applied to large and complex watersheds. Testing of convergence is difficult since the true optimum solutions are often unknown. One method to test convergence is to perform multiple replications of the optimization using the same or different optimization algorithms and comparing their results. Comparing solutions from many optimization algorithms is more robust than multiple replicates using the same algorithm as the former approach can potentially reduce chances of converging to a local minimum. To the best of our knowledge no such efforts are reported in spatial optimization convergence testing, perhaps due to the computational cost of optimization. Multi-algorithm optimization methods are known to be more efficient than a single optimization algorithm. For example, Multi ALgorithm Genetically Adaptive Method (AMALGAM) (Vrugt and Robinson, 2007) is a multialgorithm optimization method and is reported to be more efficient than a single algorithm optimization in watershed simulations (Vrugt and Robinson, 2007; Zhang et al., 2010). The method uses four widely used optimization algorithms, including the Nondominated Sorted Genetic Algorithm II (NSGAII) (Deb et al., 2002), particle swarm 
optimization (PSO) (Kennedy and Eberhart, 2001), adaptive metropolis search (AMS) (Haario et al., 2001), and differential evolution (DE) (Storn and Price, 1997).

Our efforts to compare efficacy of single and multi-algorithm optimization methods for a complex spatial optimization case study indicated that all test cases converged to below optimum solutions and/or failed to search within the full search space. This may be primarily due to the complexity of the search space. With efforts to reduce search space complexity and drawing inspiration from the notion of dividing and reducing complexity, we introduce a new spatial optimization approach in this study. This novel optimization approach is developed for complex spatial optimization problems with a multilevel optimization concept, which we refer to as Multi-Level Spatial Optimization (MLSOPT). This method splits the optimization problem into more reasonably-sized sections by dividing a large watershed into small sub-watersheds. This manuscript presents the MLSOPT algorithm and compares the approach with multiple single-level spatial optimizations using complex spatial optimization case studies. The objectives of this study were to (1) evaluate performance of single-level spatial optimization test cases using NSGA-II, PSO, and AMALGAM for complex spatial optimization case study, (2) develop a computationally efficient optimization approach for watershed scale spatial optimization, and (3) evaluate performance of the proposed MLSOPT approach with single-level spatial optimization.

\section{Methodology}

The MLSOPT approach dynamically links a watershed simulation model with an optimization algorithm, where the simulation model estimates objective functions for the sample populations generated by the optimization algorithm. The proposed approach is tested with two complex case studies to spatially optimize corn stover removal rates for maximum biofuel production having minimum environmental impacts in a $2,000 \mathrm{~km}^{2}$ watershed (Wildcat Creek watershed, Figure 1). Case study 1 was designed to minimize environmental impacts at source area scale with objective function to minimize erosion from the source agricultural fields. Case study 2 was designed to minimize pollutant loading at a specific point in the stream with objective function to minimize sediment 
loading at watershed outlet. The Soil and Water Assessment Tool (SWAT) was used in the study as the watershed simulation model to represent corn stover removal and to quantify biomass production and associated environmental impacts such as erosion from agricultural fields and sediment load at watershed outlet. The model is developed for the Wildcat Creek watershed with about 922 corn/soybean areas from where stover harvest is possible. The first optimization case study was done with single-level optimization using three popular optimization algorithms and resulting optimum solutions were compared. The three optimization algorithms included: (1) Non-dominated Sorting Genetic Algorithm-II (NSGA -II); (2) Particle Swarm Optimization (PSO); and (3) A Multi ALgorithm Genetically Adaptive Method (AMALGAM). The MLSOPT approach with AMALGAM optimization algorithm was then compared with these three test cases to evaluate the robustness of the proposed approach. Case study 2 compared single-level optimization and MLSOPT approach with AMALGAM as optimization algorithm.

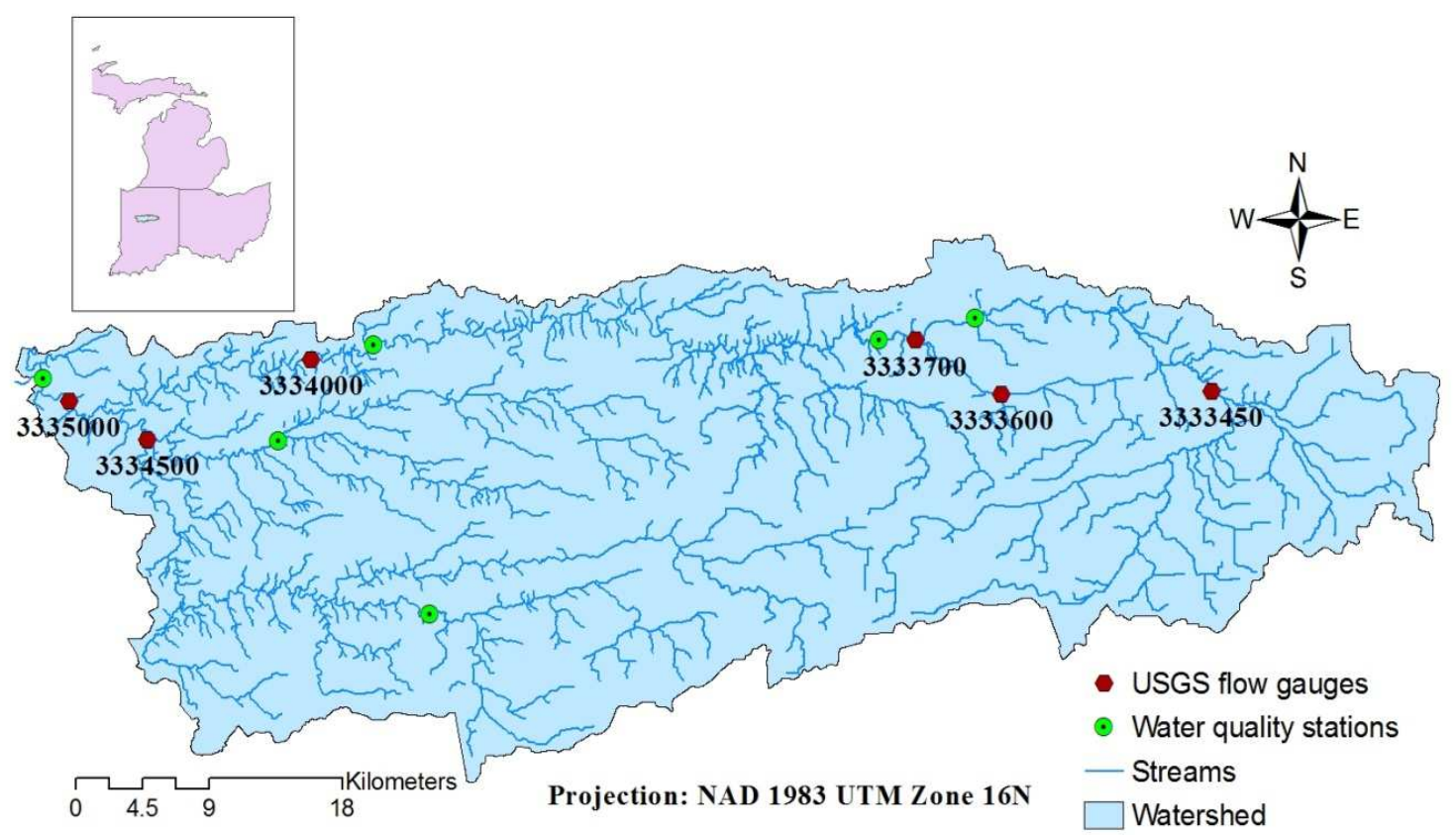

Figure 1. Location of the Wildcat Creek watershed in Indiana, USA 


\subsection{Spatial Optimization Approach: MLSOPT}

Spatial optimization at the watershed scale is inherently complex, computationally expensive, and can potentially fail to converge to an optimum solution in a large and complex search space. The proposed approach consists of two spatial levels of optimization that are performed sequentially. The first level divides the watershed into smaller sub-watersheds, each consisting of multiple field units. Optimum solutions for individual sub-watersheds are identified using the optimization algorithm and watershed simulation model. The complexity of the optimization problem is reduced significantly with sub-watershed level optimization. For example, if the watershed has 50 subwatersheds and each sub-watershed has 20 field units, which can each have 4 decision options such as four stover removal rates, the complexity is reduced from $4^{1000}$ with watershed scale single-level optimization to $4^{20}$ with sub-watershed level optimization. The individual sub-watershed optimum solutions are further optimized in the second level of MLSOPT to identify watershed scale optimum solutions. At the second level only the optimal solutions from each sub-watershed is selected which considerably increases the optimization efficiency. If the size of individual sub-watershed Pareto-front is 100 , then the complexity of second level is $100^{50}$. Thus the total complexity of MLSOPT in two levels is sum of $4^{20}$ and $100^{50}$, which is very small compared to singlelevel complexity. The approach is designed to (i) reduce the optimization complexity by splitting watershed in to smaller units, such as sub-watersheds, and identifying optimum solution individually for each sub-watershed, (ii) reduce the computational expense by parallel optimization of all sub-watersheds simultaneously, and (iii) identify watershed scale optimum solutions with the second level optimization using optimum solutions from individual sub-watersheds.

Figure 2 depicts the flowchart of the MLSOPT spatial optimization approach. The approach begins with an initial population created from the search space, with Latin Hypercube Sampling in this study. Each sample in the population denotes a feasible spatial combination and is simulated using the watershed simulation model. Objective functions $\left(\mathrm{OF}_{\mathrm{i}=1: \mathrm{nObj}, \mathrm{nsub}}\right)$ and constraints $\left(\mathrm{C}_{\mathrm{i}=1: \mathrm{nConst}, \mathrm{nsub}}\right)$ are estimated for individual subwatersheds (1:nsub) from model simulation. Initial sample and corresponding objective 
functions and constraints for each sub-watershed are linked with the individual optimization algorithm to create a next generation offspring sample for the subwatershed. The same step is done for all sub-watersheds in parallel and the offspring samples (Newsample $\mathrm{j}_{\mathrm{j}=1 \mathrm{nsub}}$ ) are merged together to create a new sample population for the watershed, as shown in Figure 3. In effect, one sample for 'nsub' sub-watersheds requires only one model simulation and this reduces the computational cost significantly. This process is continued until the user defined termination criteria are satisfied for this level. This provides optimum solutions for individual sub-watersheds as Pareto-optimal fronts (a set of compromised trade-off solutions with multiple conflicting objective functions) of objective functions.

For the second level of optimization, a lookup table is created with equally spaced optimal solutions from individual sub-watershed Pareto-optimal fronts generated from the first level of optimization. The optimization algorithm is then linked to this lookup table to find watershed level optimum solutions. This approach reduces the second level optimization search space to only combinations of best solutions from individual subwatershed, thus improving the efficiency of optimization. For source area based optimization problems (e.g. to minimize erosion from all agricultural fields as in Case Study 1), a lookup table can be created with first-level optimal solutions and corresponding objective functions. Then the second level objective function can be evaluated as summation or average of sub-watershed objective function directly from this table without a need to run the watershed model again. For example, objective function of total erosion from watershed is cumulative of erosion from all sub-watersheds. For watershed outlet based optimization problems requiring routing from among subwatersheds (e.g. to minimize sediment yield from watershed outlet as in Case Study 2) the look up table contains Pareto-optimal solutions from the first-level optimization to reduce the optimization search space as discussed above. Simulation model is used to estimate the objective function such as sediment load at watershed outlet. This will be more computationally intensive than the source area based optimization problems as model simulation is required in both levels of MLSOPT. 
Even though the current study used SWAT model as simulation model for demonstrating MLSOPT approach, any other watershed simulation model can be used with this approach, provided the model can divide a large study area into smaller subareas. Similarly, any optimization algorithm can be used in the MLSOPT approach, but AMALGAM is preferred in this study as it was found to be more efficient than single optimization algorithms and source codes were available in Matlab for which helped in easy adaptation to parallel computing. Optimization termination criterion is another important decision factor for users which could affect computation cost and is highly depended on the specific optimization problem and its complexity. The MLSOPT framework needs termination criteria defined for both levels of optimization. The current study used termination criteria as 1000 generations in all test cases as the true optimum solutions were unknown to estimate statistical convergence. Users need to carefully evaluate the trend of convergence across optimization generations to decide on appropriate convergence criteria for specific optimization problems. 


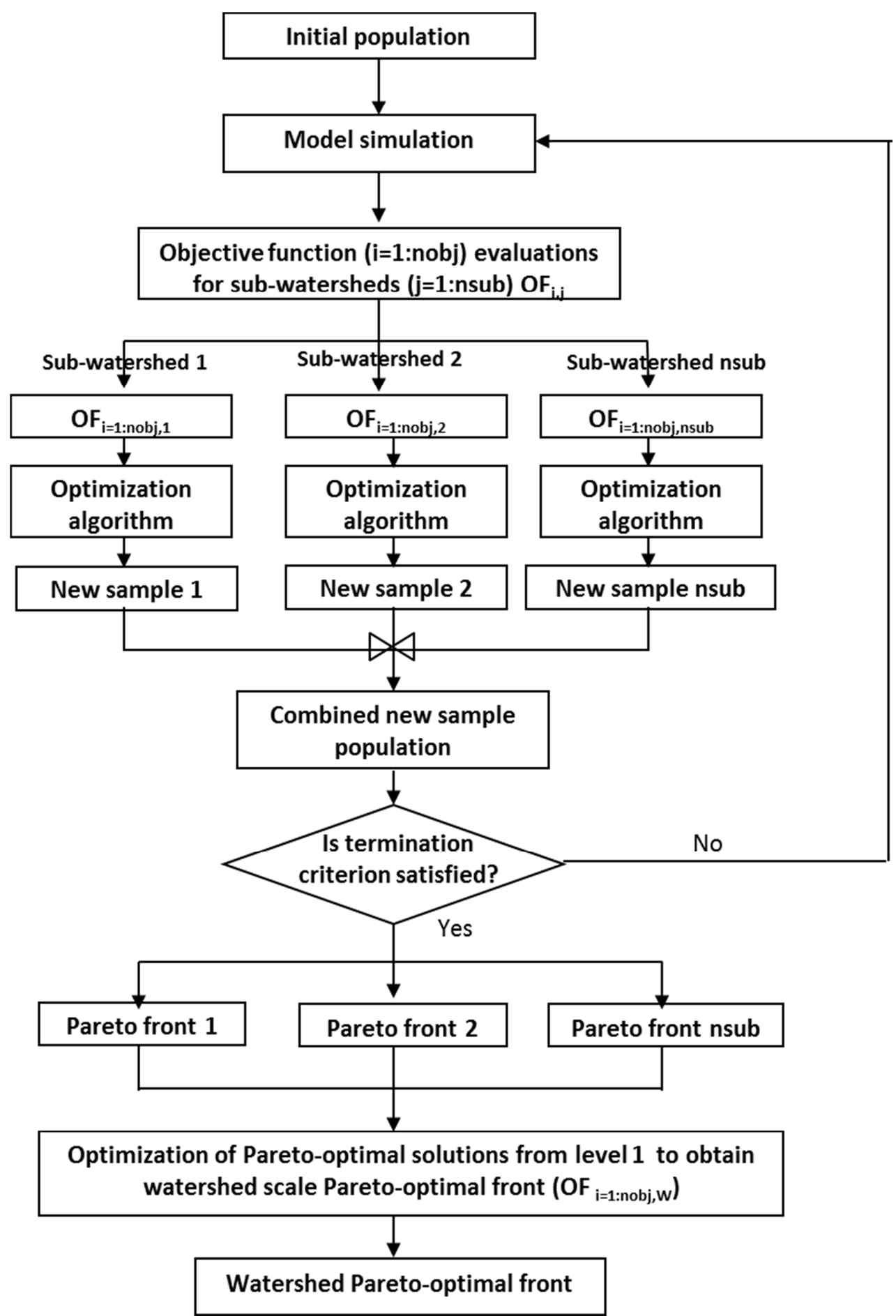

Figure 2. Flow chart of the proposed spatial optimization approach (MLSOPT) 


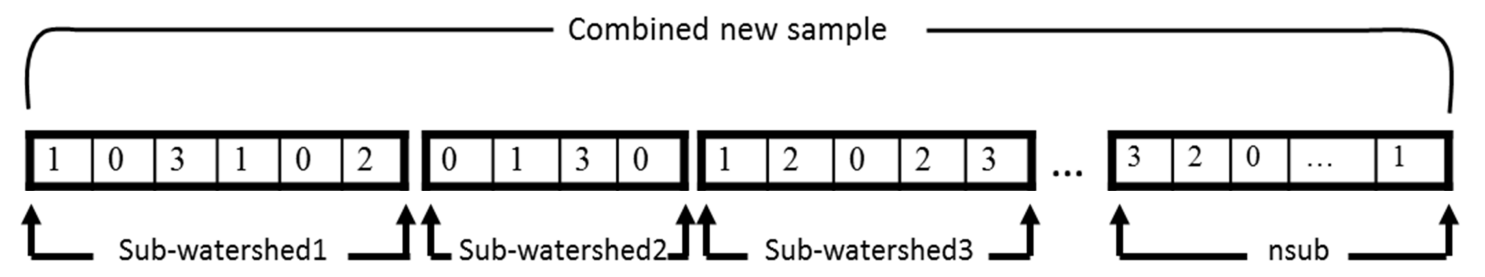

Figure 3. Merging of individual sub-watershed sample populations to one single combined sample for the watershed for simulation, numbers in each box indicates the stover removal scenario for the individual agricultural field in sub-watershed.

\subsection{Optimization algorithm}

\subsubsection{Non-dominated Sorting Genetic Algorithms II (NSGA-II)}

Genetic algorithms are the most widely used evolutionary optimization algorithms for complex multi-objective optimization problems. NSGA-II developed by Deb et al. (2002) uses non-dominated sorting in offspring generation to provide diversity in the solutions to Pareto-optimal front; it also helps in checking for premature convergence. Developer's code for NSGA-II can be obtained from http://www.iitk.ac.in/kangal/codes.shtml. The optimization parameters are case specific and are usually identified using a sensitivity analysis (Maringanti et al., 2009). In this study we tried multiple optimization replicates with different mutation probability and found 0.2 as the best performing. Similarly, this study used a 0.9 probability for crossover, meaning $90 \%$ of offspring are created through crossover of two parents, rather than asexual reproduction. Detailed sensitivity analysis of parameters is not discussed here for brevity.

\subsubsection{Particle Swarm Optimization (PSO)}

PSO is a metaheuristic stochastic multi-objective optimization method. The method is inspired from the flocking and swarm behavior of birds and fish (Kennedy and Eberhart, 1995). This method works as a group of particles (possible solutions) that is updated in every generation based on fitness of the optimum solution. Similar to genetic algorithm, PSO also starts with a random particle location and velocity, and then adjusts 
the position based on the flying experience gained by each particle in subsequent generations. The parameters for PSO were selected as recommended by Hu et al. (2003).

\subsubsection{AMALGAM}

AMALGAM is an improved evolutionary optimization algorithm employing multiple heuristic evolutionary optimization algorithms simultaneously (Vrugt and Robinson, 2007). The multi-method search with self adaptive offspring creations makes AMALGAM computationally efficient in complex, high-dimensional spatial optimization problems. The AMALGAM framework is flexible to include multiple optimization algorithms as needed. The default AMALGAM package includes four methods; NSGA-II (Deb et al., 2002), particle swarm optimization (PSO) (Kennedy et al., 2001), adaptive metropolis search (AMS) (Haario et al., 2001), and differential evolution (DE) (Storn and Price, 1997). MATLAB source code for the method can be obtained from http://faculty.sites.uci.edu/jasper/sample. Parameters for different algorithms in AMALGAM are set as recommended except for NSGA-II, which used same as in NSGA-II only scenario to maintain consistency in the results.

\subsection{Watershed simulation model: SWAT}

The Soil and Water Assessment Tool (SWAT) (Arnold et al., 1998) is one of the most widely used watershed simulation model with more than 1,700 peer-reviewed articles published on development, use, and application of the model. SWAT is a process based, distributed-parameter hydrological model designed to simulate long-term effects of various watershed management decisions on multiple ecohydrological attributes (Arnold et al., 1998). Spatially, the model utilizes watershed topographic information to divide a watershed into sub-watersheds or sub-basins. Subsequently, land use, soil, and slope information are used to further divide sub-watersheds into hydrologic response units (HRU), the smallest spatial unit upon which SWAT simulates the hydrology, sediment, nutrient and pesticide dynamics. The climatic input data required are precipitation, temperature, solar radiation, relative humidity, and wind speed on a daily or sub-daily basis. 
The HRU-level hydrology in SWAT is governed by water balance equations. The surface runoff component in SWAT can be computed using the Soil Conservation Service curve number technique or Green and Ampt infiltration method. This study uses the Soil Conservation Service curve number technique. Soil erosion is modeled at a field scale using the Modified Universal Soil Loss Equation (MUSLE) (Williams, 1975). Detailed description of the SWAT process representations and model components can be obtained from SWAT theoretical documentation (Neitsch et al., 2011). The model has been widely used in spatial optimization problems for watershed scale BMP optimization (Maringanti et al., 2009, 2011; Gitau et al., 2004; Arabi et al., 2006 among many others).

In the current version of SWAT, since HRU is defined in the model as unique combination land use, soil and slope, a single HRU in the sub-watershed can be a fragmented group of grid pixels located at different points in the sub-watershed. HRUs are independent spatial units within each sub-watershed and the hydrology and water quality routing to sub-watershed outlet is simple additive routing. For source level optimization problems, a lookup table can be created with biomass yield and water quality simulation with baseline and stover removal options for all the individual HRUs. This lookup table can be used as pseudo simulator for optimization which could give same simulation result as SWAT (Cibin, 2013). However the current study used the general optimization framework approach where the simulation model is directly linked with model as the study was designed to evaluate MLSOPT approach in a general framework where any simulation can be used. The SWAT model is also evolving further to include landscape routing with in sub-watershed (Arnold et al., 2010).

\subsection{Description of case studies - optimal corn stover removal for biofuel production}

\subsubsection{Optimization problem description}

The spatial optimization problem for the two case studies was designed to identify optimum corn stover removal rates from the Wildcat Creek watershed to maximize stover production and minimize environmental impacts. The HRUs from which stover could be harvested were all row crop (corn/soybean) HRUs, and these were considered as the 
variables for the optimization problem. Three stover removals rates-38\%, 52\%, and $70 \%$, as proposed by Brechbill and Tyner (2008) —along with the baseline of 0\% (no stover removal) were considered as the options available for each corn/soybean area. We previously quantified the long-term environmental impacts of corn stover removal in Wildcat Creek watershed using the SWAT model and reported an increase in soil erosion and sediment loading in streams with corn stover removal (Cibin et al., 2012). Two conflicting objective functions were considered in both unconstrained optimization case studies. The first objective function was to maximize corn stover harvested from the watershed. The second objective function was to minimize soil erosion in the watershed for case study 1 and minimize sediment load at watershed outlet for case study 2 as shown below:

Case Study 1: $\operatorname{minimize}\left\{-1 * \sum_{i h r u=1}^{n H R U}\right.$ StoverBiom $_{i h r u}, \sum_{i h r u=1}^{n H R U}$ Erosion $\left._{i h r u}\right\}$ Case Study 2: minimize $\left\{-1 * \sum_{i h r u=1}^{n H R U}\right.$ StoverBiom $_{\text {ihru }}, \quad$ Sed Load $\left._{\text {Outlet }}\right\}$

Variables: corn and soybean HRUs, a total of 922 HRUs.

Placement options: corn stover removal $(0 \%, 38 \%, 52 \%$, or $70 \%)$ from corn/soybean areas.

In general cases of improving river health, objective function to minimize impacts at source area similar to case study-1 should be preferred such that every point in the stream is given same preference. At specific cases to improve water quality at one specific point in the river, e.g. for a drinking water supply intake or some ecologically critical area in stream, objective functions defined similar to case study-2 may be more appropriate. Management and conservation practices are implemented at the source area (agricultural field) so in general source level optimization to identify critical areas in the watershed could be more effective than watershed outlet based optimization for such objectives. 


\subsubsection{Study area description and SWAT model development}

The case studies were conducted in Wildcat Creek watershed (USGS 8-digit HUC 05120107), located in north-central Indiana (Fig 1). Wildcat Creek is approximately 150 $\mathrm{km}$ long and drains to the Wabash River, with a drainage area of $2,083 \mathrm{~km}^{2}$. The watershed is predominantly agricultural with about $70 \%$ corn and soybean planted in rotation, 13\% urban, 9\% forest and 5\% pasture area (USDA-NASS, 2009). ArcSWAT 2009.93.5 was used to parameterize the study area. The elevation data (DEM) from National Elevation Dataset (NED NAD 83, http://seamless.usgs.gov, $30 \mathrm{~m}$ resolution), land use data from the Cropland Data Layer (CDL, 2009) (www.nass.usda.gov/research/Crop-land/SARS1a.htm) and soil information obtained from the USDA Natural Resources Conservation Service (NRCS) Soil Survey Geographic Database (SSURGO) were used to delineate the watershed and to estimate topographic, land use and soil parameters. Three slope classes were used for HRU classification; $0-2 \%, 2-5 \%$ and above $5 \%$. The watershed was divided into 84 subwatersheds and 1,898 HRUs, out of which corn and soybean constituted 922 HRUs.

Measured stream flow data from the USGS gauging stations (Fig 1) for 19952009 was used for model evaluation in which the first 10 years of data were used for model calibration and the remaining 5 years for model validation. The model was calibrated for flow and sediment yield at the watershed outlet using basin level parameters. The measured sediment concentrations were available only for a few days each year. Therefore, the LOADEST model (Runkel et al., 2004) was used to estimate mean annual sediment loading and 95\% confidence intervals around the mean values. Detailed descriptions of data availability and SWAT model development, model calibration and validation for the watershed can be obtained from Cibin et al. (2012). The calibrated model was used to simulate effects of stover removal rates. The model is capable of adjusting soil temperature, energy balance, water balance, nutrient cycle and erosion parameters based on residue cover. Detailed discussion on stover removal scenarios and their representation in SWAT can be obtained from Cibin et al. (2012). 


\subsection{Performance evaluation of optimal fronts}

Performance evaluation of Pareto-fronts for multi-objective optimization problems is challenging due to the difficulty in finding analytical expression of the Pareto-front and in most cases the true Pareto-optimal fronts are unknown. Major goals in performance evaluation of Pareto-fronts are to check convergence of the front to the reference Pareto-front and to have multiple well-distributed diverse solutions in the Pareto-front. In this case study, the best obtained Pareto-front from the test cases is considered as the reference Pareto-front to estimate the relative performance of optimal fronts, since the true Pareto-optimal front is unknown. The Pareto-front from MLSOPT with 1,000 generation in two stages is identified as the reference front. Three performance evaluation indices; gamma index, delta index (Deb et al., 2001) and Relative hypervolume index (Zitzler and Thiele, 1999) were used to evaluate the quality of Paretofronts obtained with respect to the reference Pareto-front.

Gamma index measures the extent of closeness or convergence of Pareto-front to the reference Pareto-front. The minimum Euclidean distance of individual Pareto solution with the reference Pareto solution is computed and the average of these Euclidean distances is Gamma index, where closeness to zero indicates convergence. Delta index indicates the spread of a Pareto-front. A well distributed Pareto-front would have delta index close to zero. The relative hypervolume metric evaluates the convergence and spread of a Pareto-front to the reference front in a single index. The index is estimated as one minus ratio of Pareto front hypervolume to the reference front hypervolume. The closeness of the relative hypervolume to zero indicates closeness of the Pareto front to the reference front. A more detailed discussion on indices and mathematical formulations can be obtained from Deb (2001) and Vrugt and Robinson (2007).

\section{Results and discussion}

\subsection{Calibration and validation of model}

The SWAT model for Wildcat creek watershed reported in Cibin et al. (2012) was further calibrated and validated for stream flow and sediment yield at the watershed 
outlet. The model calibration using basin level parameters (Table 1) resulted in a daily stream flow $\mathrm{R}^{2}$ of 0.86 and Nash-Sutcliffe efficiency of 0.86 during calibration and $\mathrm{R}^{2}$ of 0.81 and Nash-Sutcliffe efficiency of 0.80 during validation, respectively, at the watershed outlet. Figure 4(A) shows the scatter pot of USGS measured and SWAT simulated daily stream flow for the gauging station near watershed outlet. The stream flow was slightly overestimated by the model in low flow regimes; the average daily flow was simulated as $26.7 \mathrm{~m}^{3} / \mathrm{s}$ compared to the measured mean of $24.4 \mathrm{~m}^{3} / \mathrm{s}$. Daily and monthly calibration and validation statistics for stream flow of gauging stations in the watershed are given in Table 2. Calibration and validation statistics indicate very good model performance based on criteria described by Engel et al. (2007). Figure 4(B) shows the SWAT simulated and LOADEST estimated annual sediment loading at the watershed outlet. The graphical evaluation of SWAT simulated annual sediment loading was within the $95 \%$ confidence interval estimated using LOADEST. SWAT model simulations were outside the 95\% LOADEST estimated confidence interval for a few low flow years; this may be due to the fact that stream flow was overestimated by the model in low flow periods. The model was not calibrated further to reduce discrepancy between SWAT simulated and LOADEST estimated mean sediment loads considering uncertainty in LOADEST estimated values. 
Table 1: SWAT parameters calibrated in the study and calibrated parameter values

\begin{tabular}{|l|l|l|l|l|l|}
\hline $\begin{array}{l}\text { SI } \\
\text { No }\end{array}$ & $\begin{array}{l}\text { Parameter } \\
\text { name }\end{array}$ & Process & Default & Range & $\begin{array}{l}\text { Calibrated } \\
\text { value }\end{array}$ \\
\hline 1 & SFTMP & Snow fall & 1 & -5 to 5 & -0.693 \\
\hline 2 & SMTMP & Snow melt & 0.5 & -5 to 5 & 0.5 \\
\hline 3 & SMFMX & Snow melt & 4.5 & 0 to 10 & 6.925 \\
\hline 4 & SMFMN & Snow melt & 4.5 & 0 to 10 & 4.5 \\
\hline 5 & TIMP & Snow melt & 1 & 0.01 to 1 & 0.034 \\
\hline 6 & ESCO & Soil evaporation & 0.95 & 0.01 to 1 & 0.596 \\
\hline 7 & SURLAG & Surface runoff & 4 & 0.5 to 12 & 0.5 \\
\hline 8 & SPCON & Sediment transport & 0.0001 & 0.0001 to 0.01 & 0.0001 \\
\hline 9 & SPEXP & Sediment transport & 1 & 1 to 2 & 1.5 \\
\hline
\end{tabular}

Table 2: Daily and monthly calibration and validation statistics for stream flow in Wildcat Creek watershed

\begin{tabular}{|c|c|c|c|c|c|c|c|c|c|c|}
\hline \multirow[t]{3}{*}{ Station } & \multirow{3}{*}{$\begin{array}{c}\text { Station } \\
\text { ID }\end{array}$} & \multirow{3}{*}{$\begin{array}{c}\text { Drainage } \\
\text { area } \\
\left(\mathbf{k m}^{2}\right)\end{array}$} & \multicolumn{4}{|c|}{ Calibration statistics } & \multicolumn{4}{|c|}{ Validation statistics } \\
\hline & & & \multicolumn{2}{|c|}{ Daily } & \multicolumn{2}{|c|}{ Monthly } & \multicolumn{2}{|c|}{ Daily } & \multicolumn{2}{|c|}{ Monthly } \\
\hline & & & $\overline{\mathbf{R}^{2}}$ & $\mathbf{N S}$ & $\overline{\mathbf{R}^{2}}$ & $\mathbf{N S}$ & $\mathbf{R}^{2}$ & $\mathbf{N S}$ & $\overline{\mathbf{R}^{2}}$ & $\mathbf{N S}$ \\
\hline Wildcat near Kokomo & 3333700 & 614 & 0.71 & 0.70 & 0.90 & 0.90 & 0.66 & 0.64 & 0.98 & 0.94 \\
\hline Wildcat near Owasco & 3334000 & 1009 & 0.84 & 0.84 & 0.94 & 0.93 & 0.76 & 0.73 & 0.93 & 0.87 \\
\hline Southfork Creek Lafayette & 3334500 & 642 & 0.79 & 0.79 & 0.92 & 0.91 & 0.74 & 0.69 & 0.88 & 0.81 \\
\hline Wildcat near Lafayette & 3335000 & 2045 & 0.86 & 0.86 & 0.92 & 0.92 & 0.81 & 0.80 & 0.93 & 0.90 \\
\hline
\end{tabular}
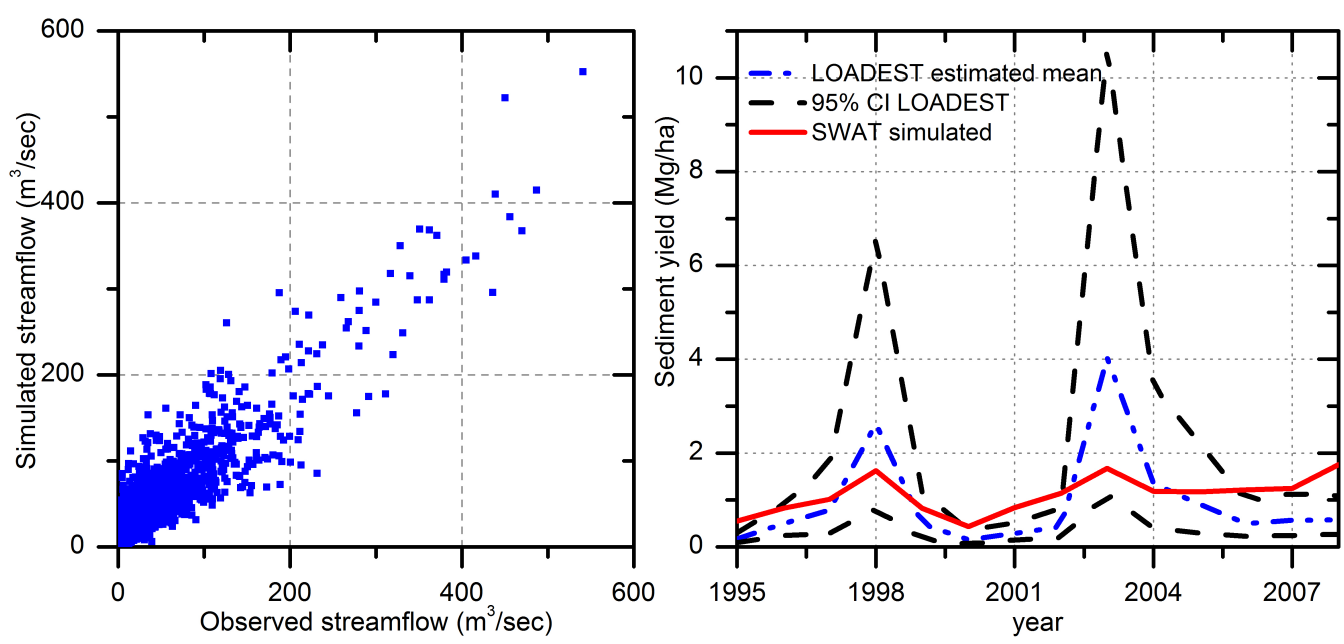

Figure 4. (A) Scatter plot of observed and simulated daily stream flow. (B) Time series plot of SWAT simulated, LOADEST estimated mean and 95\% confidence interval annual sediment yield (1995-2008) 


\subsection{Source area based spatial optimization: Case study 1}

The source area based optimization case study was first done in single-level optimization with three optimization algorithms (Figure 5.a) using NSGA-II (blue dots), PSO (purple diamonds) and AMALGAM (green diamonds). Optimization test cases were evaluated with the optimum stover removal case study for Wildcat Creek watershed for a simulation period of four years (2000-2004). All test cases were done with population size of 100 with 1000 generations as termination criteria, resulting in 100,000 model runs. Each test case took about 4 days of simulation time on $2.3 \mathrm{GHz}$ AMD Opteron 6176 processors with 38 parallel MATLAB workers. The optimization parameters, such as mutation and crossover probability, were considered to be same for all applicable cases. The test case with AMALGAM and PSO provided good spread of solutions in entire search space, but the solutions obtained were not optimal when compared with NSGA II test case. AMALGAM which includes NSGA-II and PSO had better convergence than PSO alone. NSGA II test case had better solution convergence, but the search space was limited to a small region. The results indicated failure of single-level optimization in finding optimal tradeoff solutions, which could be due to the complexity of search space. 

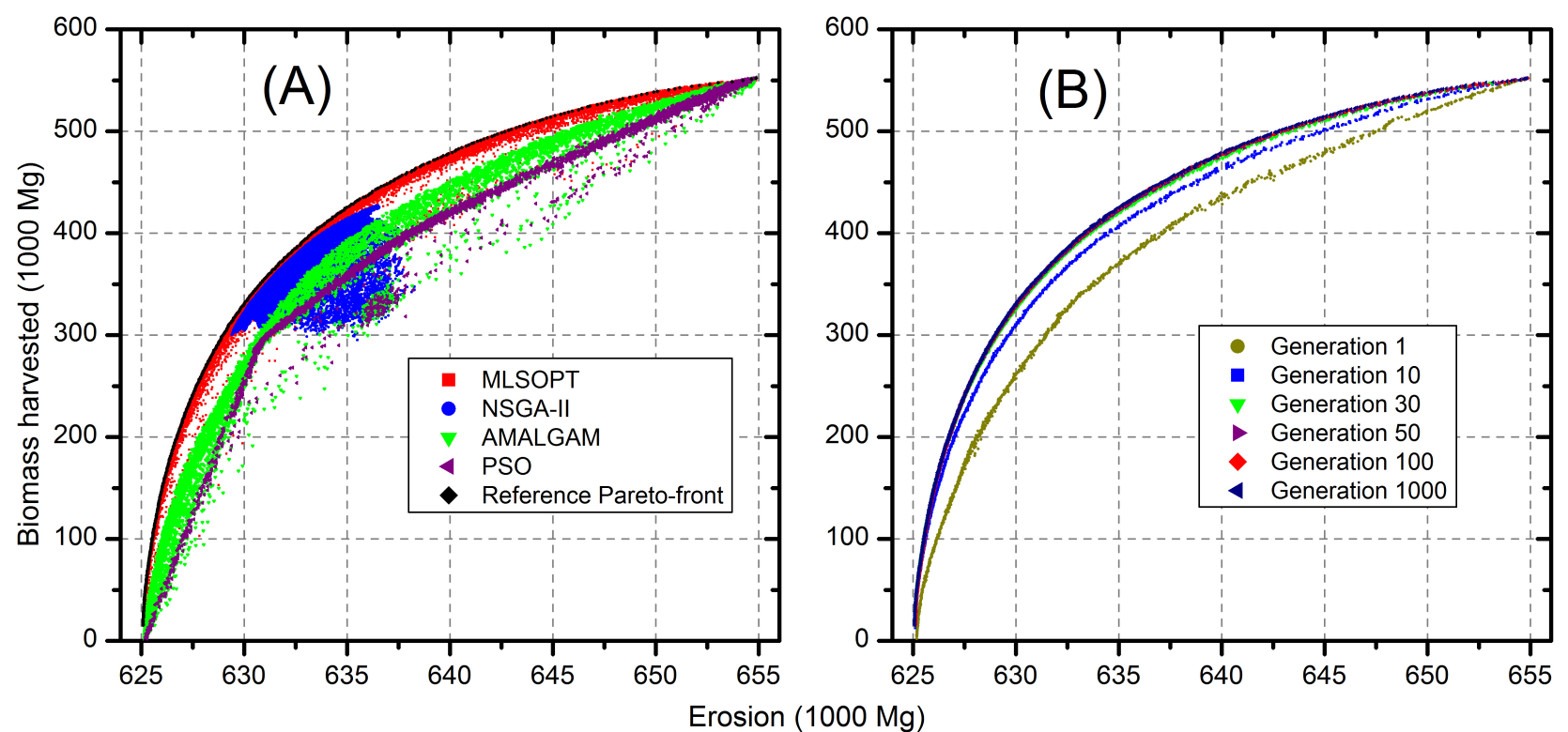

Figure 5. Optimization convergence (A) comparison of MLSOPT with NSGA -II, PSO, AMALGAM (B) plot of watershed level Pareto-fronts for MLSOPT developed with optimal fronts after 1, 10, 30, 50, 100 and 1000 sub-watershed level generations. The second level termination criterion was 1000 for MLSOPT.

The Pareto-front from the Multi-Level Optimization (MLSOPT) was better in convergence and spread of front comparing to the three single-level test cases (Fig.5). The better Pareto-front with MLSOPT indicates the complexity of solution search space as the reason for single-level optimization test case failure. With four stover removal scenarios and 922 HRU's, the complexity with single-level optimization was $4^{922}$. With 922 HRUs, NSGA-II failed to search in extreme scenarios such as no stover removal in the watershed or $70 \%$ stover removal from all fields. The complexity is reduced considerably with the two level optimization approach; the maximum complexity with first level of optimization was $4^{27}$ for sub-watershed which had a maximum of 27 corn/soybean HRU's in any sub-watershed, which the optimization algorithm could search effectively. MLSOPT approach requires convergence testing and termination criteria at each level of optimization; sub-watershed level and watershed level optimization. The current case study required SWAT simulations only for first level (subwatershed level) optimization and second level (watershed level) was done with lookup 
table as previously discussed. Improving computation efficiency in first level was critical for this case study as computational time for level one was about four days with parallel computing while level two required only $12 \mathrm{~min}$ in serial computing. Thus sub-watershed level convergence testing was done by doing the second level optimization 1000 times with first level termination criteria from 1 to 1000 and fixed 1000 generation termination criteria for watershed level. Figure 5 (B) shows the few Pareto-fronts from that exercise for the MLSOPT approach with different sub-watershed level optimization generations. Very little improvement in watershed level convergence was observed between optimizations done with 30 and 50 generations in the sub-watershed level optimization and no improvements beyond 50 generations. This indicates the proposed approach requires less than 50 generations in sub-watershed level optimization. The total MLSOPT optimization simulation time can be reduced by considering 50 generations as termination criteria for sub-watershed level to about 5 hours with $2.3 \mathrm{GHz}$ AMD Opteron 6176 processors using 38 parallel MATLAB workers, which is approximately 20 folds more efficient compared to single-level optimization with 1000 generation termination criteria. The optimization convergence may vary with the number of HRUs in each subwatershed, so it is better to have a larger number of small sub-watersheds in the watershed. Increasing the number of sub-watersheds will not increase the computational complexity in first level since all sub-watersheds are optimized in parallel, and the second level optimization may not be very complex as it considers only best solutions from each sub-watershed.

As discussed above, the proposed approach was implemented with two levels of optimization. Figure 6 shows the optimization solutions (blue dots) for three representative sub-watersheds in the watershed. The red dots in Figure 6 show the Pareto optimal front for the sub-watershed after the first level of optimization. These optimal fronts (red dots) were generated as equally spaced points used to create the lookup table for second level of watershed scale optimization. In this study, the maximum biomass potential solution from equally spaced bins of erosion values was selected to create lookup table. The lookup table included optimum sample combinations along with objective function values. For the case study, SWAT model simulations were done only 
in the first level, and second level used the lookup table created from first level for objective function evaluations.
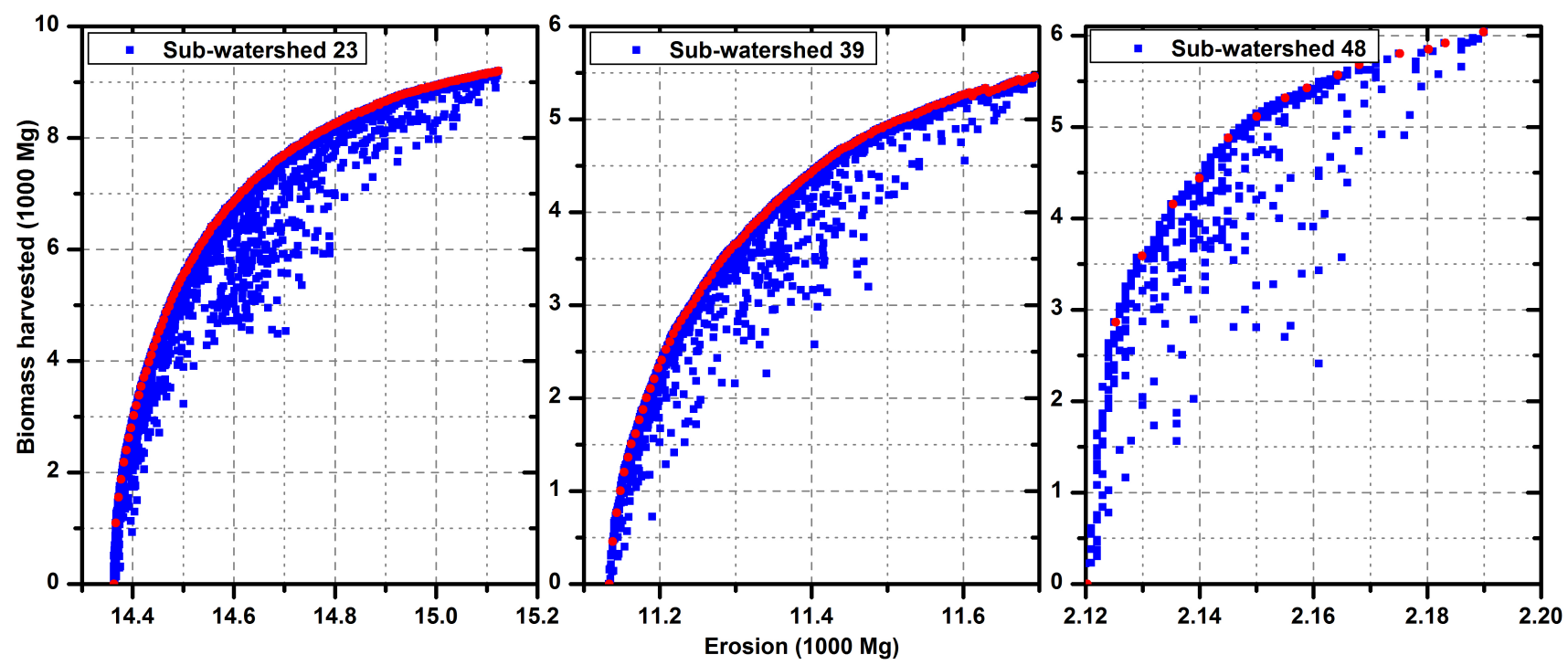

Figure 6. Individual sub-watershed optimization scatter plots for three sub-watersheds in the watershed; each dot point is a spatial placement combination for sub-watershed. Red dots show the Pareto-optimal fronts for these sub-watersheds and are used in lookup table for the watershed scale optimization.

\subsection{Watershed outlet based spatial optimization: Case study 2}

The watershed outlet based optimization case study compared MLSOPT with single level optimization using AMALGAM (Figure 7). In this case study the subwatershed level optimum solutions after 50 generations from case study 1 was chosen for second level (watershed level) MLSOPT. The second level MLSOPT and single level optimization was done with population size of 100 with 1000 generations as the termination criterion similar to the case study 1 . Optimization results indicate better convergence for MLSOPT approach compared to single level optimization (Figure 7). Both test scenarios provided good spread of solutions across the search space. 

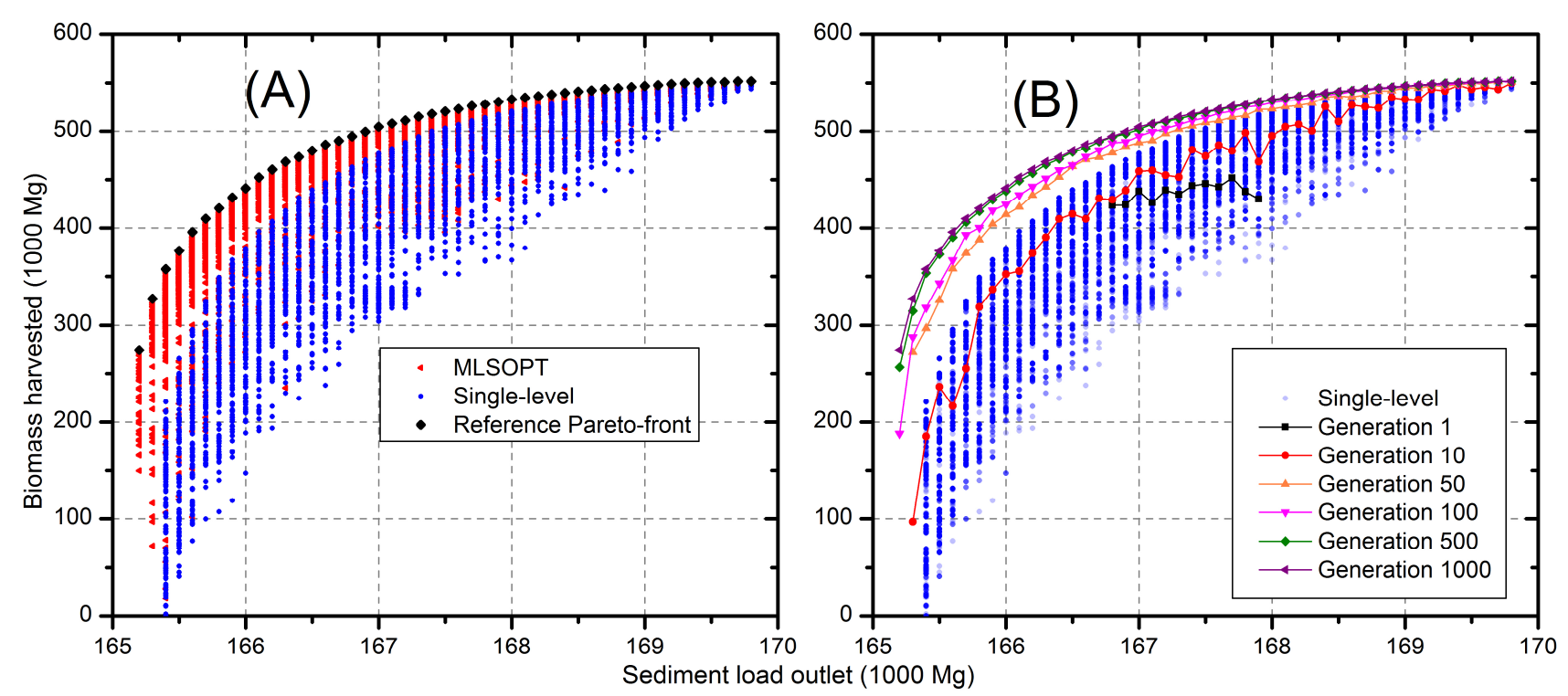

Figure 7. Optimization convergence (A) comparison of MLSOPT with single level optimization for watershed outlet based optimization case study (case study 2) (B) comparison of watershed level Pareto fronts of MLSOPT after 1, 10, 50, 100, 500 and 1000 watershed level generations. First level termination criteria was set as 50 for MLSOPT.

In this case study, the termination criteria for both sub-watershed and watershed level of MLSOPT optimization is critical as model simulation is required for both levels. Convergence of the first level was evaluated using case study 1 , and this case study evaluated convergence of second level (watershed level) optimization. The MLSOPT approach was able to find better solution in 50 generations than Pareto front obtained from single level optimization scenario after 1000 generations (Figure 7 (B)). The convergence after 100 generations was found to be gradual.

\subsection{Performance evaluation of MLSOPT approach}

In line with the graphical comparison (Figure 5), various performance statistics used to test the convergence also showed (Figure 8 and 9) the robustness of MLSOPT in convergence to the other optimizations algorithms evaluated in this study. The best 
obtained Pareto-front after 1000 generations was considered as the reference Paretooptimal front for estimating performance evaluation statistics. Figure 8 shows the performance statistics of the test cases across generations with case study 1 . Performance statistics of sub-watershed level optimization for MLSOPT is evaluated in this case study with second level termination criteria as 1000 generations. The gamma index evaluating solution convergence reached about 3.7 by 50 generations for MLSOPT and very little improvement was observed after 50 generations. NSGA-II had next best gamma index of 6 in about 1000 generations. As mentioned earlier, both PSO and AMAGLAM had poor convergence with relatively higher gamma index values. Delta index evaluating the diversity or spread of solutions across search space indicated high value (about 0.8) for NSGA-II and low value (about 0.4) for the other three cases which had good spread of solutions. Relative hypervolume matric considering both convergence and spread of solutions in one index clearly shows the supremacy of MLSOPT over the other test cases. Relative hypervolume was 0.01 in 50 generations for MLSOPT, while AMALGAM had 0.08, PSO had 0.2 and NSGA-II had 0.85 after 1000 generations, respectively. 

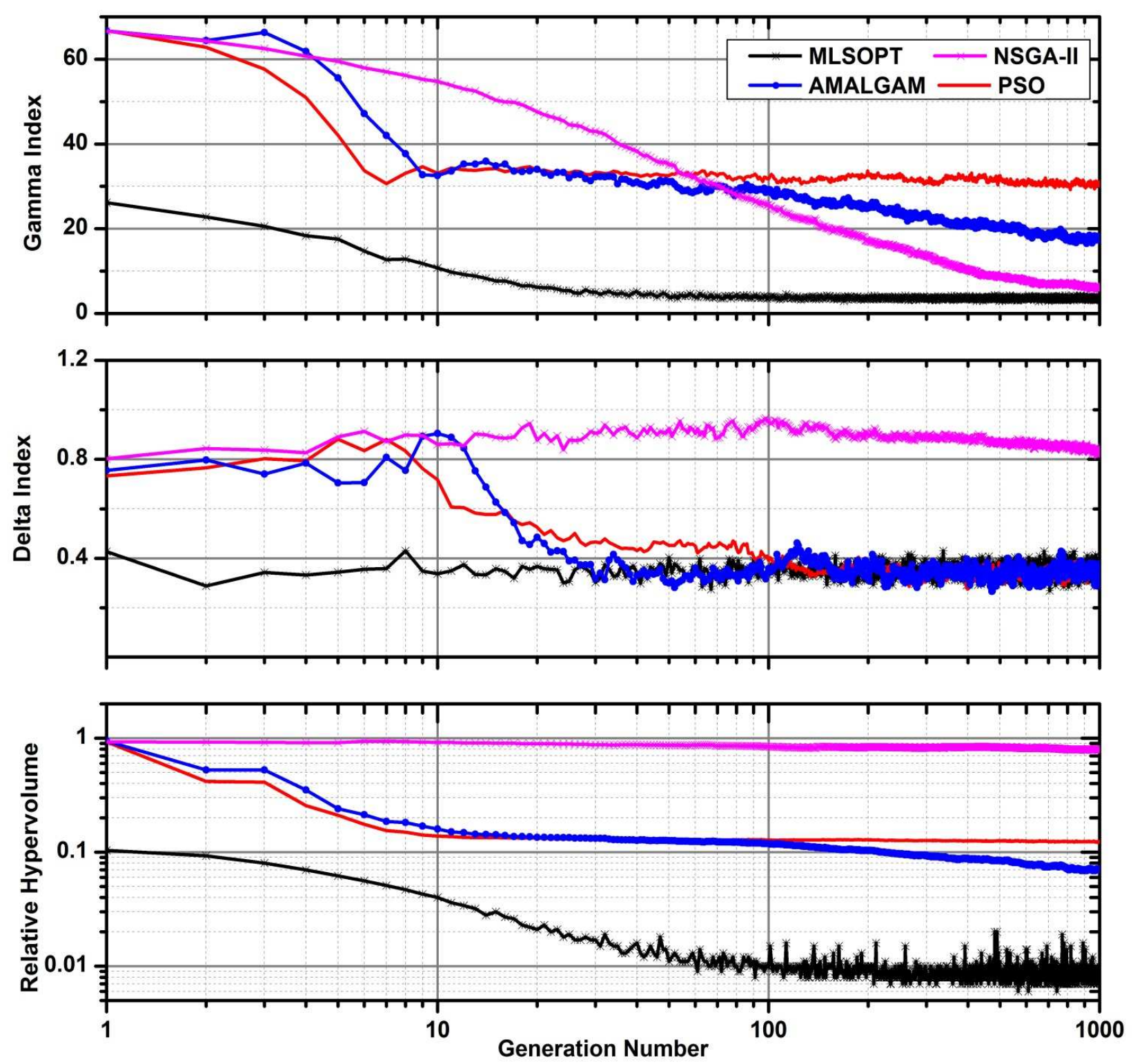

Figure 8. Illustration of efficient convergence of the new spatial optimization approach for case study 1; performance metrics of convergence for optimization algorithms NSGA-II, PSO, AMALGAM and the new approach (MLSOPT). The second level termination criterion was 1000 for MLSOPT.

The performance evaluation of second level (watershed level) for MLSOPT was conducted with case study 2 (Figure 9). The best obtained Pareto-front from case study 2 (Figure 7) was used as the reference Pareto-front for statistical evaluations. Relative hypervolume matric for MLSOPT was 0.01 in 250 generations while single algorithm optimization using AMALGAM had 0.08 relative hypervolume after 1000 generations. 
This clearly indicates the robustness of MLSOPT approach compared to single level optimizations. For a termination criteria of relative hypervolume less than 0.01, MLSOPT converged in 250 generations (i.e., total 300 generations including 50 generations from sub-watershed level optimization) and single level optimization with AMALGAM failed to converge. If the termination criteria was defined as relative hypervolume less than 0.01 or maximum number of generations equal to 1000, MLSOPT was three times computationally efficient than the single level optimization for case study 2 .

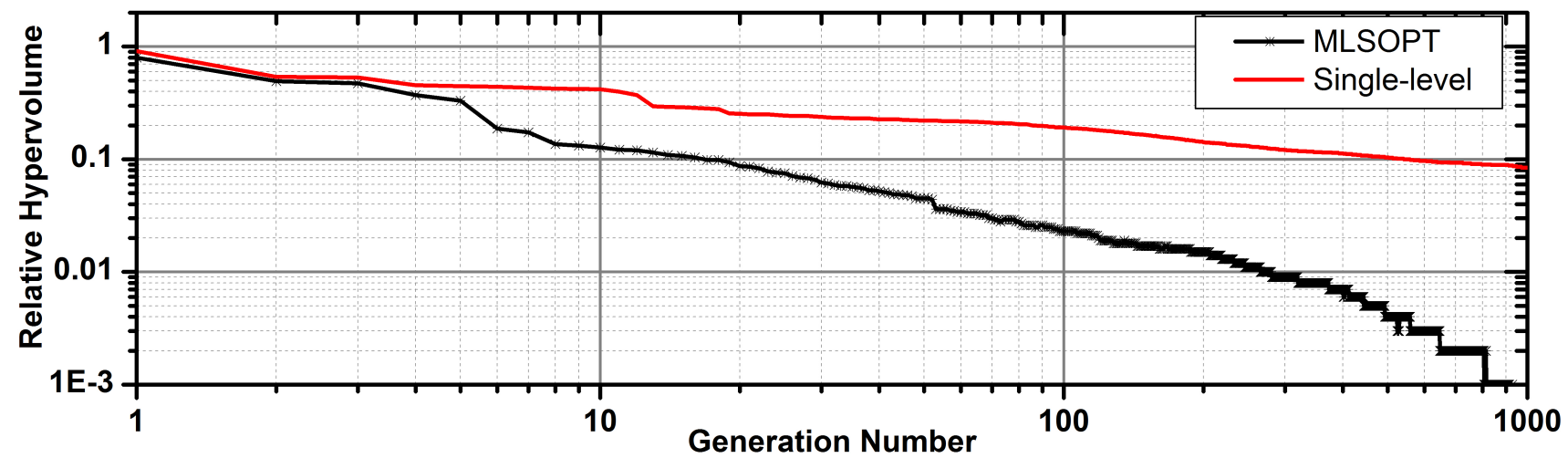

Figure 9. Relative hypervolume index comparison of MLSOPT and single level optimization from case study II. The termination criteria for sub-watershed level for MLSOPT was 50 generations. 

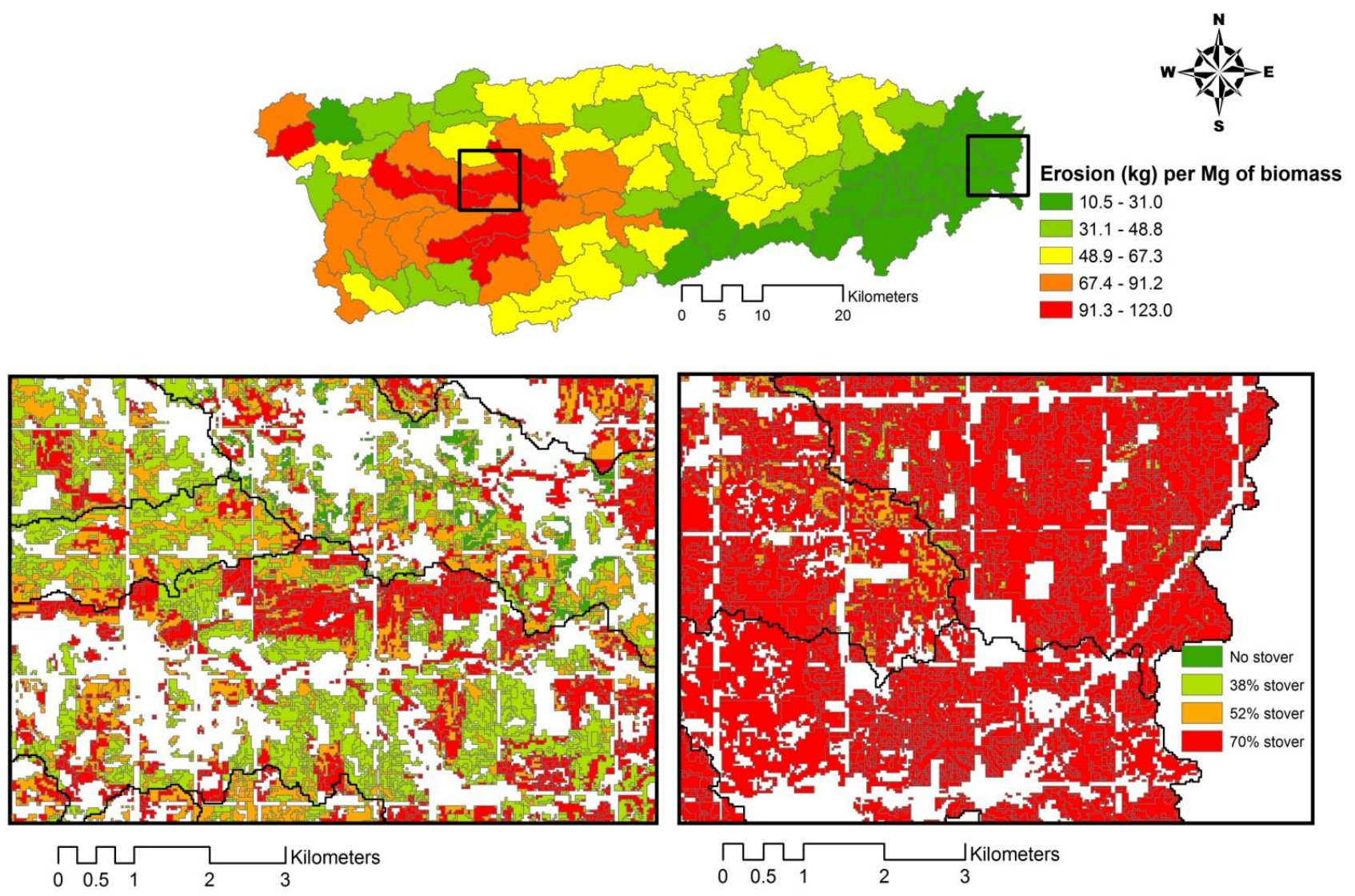

Figure 10. Spatial distribution of optimization result of case study I for the watershed. (Top) spatial variability of impact of biomass removal on erosion for sub-basin in watershed. (Bottom) Spatial distribution of stover removal rates with watershed target of $500,000 \mathrm{Mg}$ biomass for high biomass removal sensitive (Left) and low sensitive (Right) region in watershed.

\subsection{Optimal stover removal- spatial sensitivity of biomass removal}

Figure 10 (Bottom) shows the spatial distribution of stover removal for the optimum solution resulting in $500,000 \mathrm{Mg}$ of biomass harvested (one solution from Pareto optimal front) from two regions in the watershed for case study-1. It is clear that the spatial distribution of stover removal rates varies considerably within the watershed. Figure 10 (Bottom-right) shows 70\% stover removal rate in most HRU's in the region while figure 10 (Bottom-left) shows mostly $0-38 \%$ stover removal from the majority of HRU's for the same scenario of $500,000 \mathrm{Mg}$ of biomass removed from the watershed. 
Figure 10 (Top) shows the spatial variability of erosion with biomass removal indicating the spatial sensitivity to characteristics of the sub-basin. A simple correlation analysis was done between various model parameters and erosion rate per biomass removal to understand the significance of individual processes. The correlation analysis (Table 3) indicates parameters related to MUSLE, which is used to simulate erosion in the model, are highly correlated with erosion rate. Time of concentration was also found negatively correlated with stover removal sensitivity which is expected as time of concentration increases the model simulates more sediment settling before reaching to the sub-basin outlet. Other parameters such as curve number, hydrological soil group, initial moisture content, and available water capacity were moderately correlated (correlation coefficients near 0.4 ). This indicates the requirement of hydrologic simulations along with erosion simulations in stover removal studies. Overland Mannings $\mathrm{n}$ was not correlated with stover removal sensitivity since Mannings $n$ for all row cropped fields were considered the same in the model. Figure 10 also shows the robustness of the new optimization approach by allocating higher stover removal rates in low sensitivity areas and low removal rates in high sensitivity regions of the watershed. This also indicates the requirement of second level of optimization which identifies optimum solutions based on the area sensitivity.

Table 3: Correlation of sub-basin model parameters* with biomass harvest sensitivity; erosion $(\mathrm{kg})$ per $\mathrm{Mg}$ of biomass harvested.

\begin{tabular}{|l|c|}
\hline \multicolumn{1}{|c|}{ Model parameter } & Correlation coefficient \\
\hline Curve number & 0.40 \\
\hline Hydrological soil group & 0.44 \\
\hline USLE K factor & 0.71 \\
\hline USLE P factor & -0.80 \\
\hline USLE LS factor & 0.85 \\
\hline Available water capacity $(\mathrm{mm})$ & -0.40 \\
\hline Initial soil moisture(mm) & -0.39 \\
\hline Slope of HRU's & 0.85 \\
\hline Slope length of HRU's & -0.80 \\
\hline Overland Manning's N & 0.03 \\
\hline Time of concentration(hr) & -0.74 \\
\hline
\end{tabular}

*Parameters were area weighted at sub-basin level for all corn/soybean HRU's from which biomass harvested 


\section{Conclusions}

A two level optimization approach was developed for solving complex spatial optimization problems. The robustness of developed optimization approach is discussed with two case studies formulated for complex spatial optimization of identifying optimal stover removal from a large watershed. The case studies used SWAT model for objective function evaluations and AMALGAM as the optimization algorithm. The study also compared the new approach with three other evolutionary optimization algorithms used in single-level optimizations. Comparisons showed the proposed approach, MLSOPT, as superior in convergence and in computational efficiency. The approach was developed with concept of distributing complexity of the optimization problem by dividing large watershed in to small subareas.

The case study optimization to identify optimum stover removal rates with minimum impacts on erosion resulted in a Pareto-front that indicated maximum harvestable stover with corresponding minimum erosion rate. The study also indicated that erosion rate with stover removal was spatially sensitive across different regions in the watershed. Correlation studies indicated the requirement of watershed models which can consider both erosion and hydrology together for these kinds of studies. The case studies showed the effectiveness of MLSOPT in its convergence and robustness in covering the entire search space. The major advantages of MLSOPT approach are:

1. The MLSOPT is robust in convergence towards optimal solution: both case studies indicated that the approach is better in convergence compared to some of the best available single-level optimization approaches.

2. The approach is computationally efficient compared to traditional single-level optimization approaches: the new approach was 20 times computationally efficient in case study 1 and three times efficient in case study 2 compared to single-level optimization approaches.

3. The approach can be used in solving more complex optimization problems than the case studies discussed by utilizing the framework in more than two 
levels. Solutions from intermediate levels of optimization can also be used for decision making.

4. MLSOPT can be used with any watershed model and optimization algorithm.

5. Any existing complex watershed scale optimization can be adapted to the new approach very easily.

6. MLSOPT can be easily adapted to utilize parallel computing facilities, if available

7. Users can obtain Matlab based source codes for the case studies discussed from https://engineering.purdue.edu/ecohydrology/index.html

The MLSOPT is proposed as a novel concept in this study and needs further validations with more diverse test cases to evaluate the robustness of the approach. At present, MLSOPT require user judgments on defining the size of sub-watersheds, the size of solutions in sub-watershed level Pareto-front to create lookup table etc. The approach requires optimization parameters such as termination criteria, mutation/cross over probability etc. for one extra level of optimization, and may require additional user expertise with the specific problem to identify these parameters effectively. However, the approach opens more prospects in spatial optimization research with options for studying different possible optimization scenarios and comparisons across optimization results.

\section{Acknowledgements}

This material is based upon work supported by the Department of Energy under Award Number DE-EE0004396 and USDA-NIFA under Award Number 2009-5113006029. Authors acknowledge Dr. Jasper Vrugt for generously sharing MATLAB codes for AMALGAM.

Disclaimer: "This report was prepared as an account of work sponsored by an agency of the United States Government. Neither the United States Government nor any agency thereof, nor any of their employees, makes any warranty, express or implied, or assumes any legal liability or responsibility for the accuracy, completeness, or usefulness of any information, apparatus, product, or process disclosed, or represents that its use would not 
infringe privately owned rights. Reference herein to any specific commercial product, process, or service by trade name, trademark, manufacturer, or otherwise does not necessarily constitute or imply its endorsement, recommendation, or favoring by the United States Government or any agency thereof. The views and opinions of authors expressed herein do not necessarily state or reflect those of the United States Government or any agency thereof." 


\section{References}

Arabi, M., R. S. Govindaraju, and M. M. Hantush 2006, Cost-effective allocation of watershed management practices using a genetic algorithm, Water Resour. Res., 42, W10429, doi:10.1029/2006WR004931.

Arnold J G, Srinivasan R, Muttiah R S, and Williams J R. 1998, Large area hydrologic modeling and assessment - Part 1: Model development, J. Am. Water Resour. Assoc. 34(1): 73-89.

Arnold J G, Allen P M, Volk M, Williams J R, and D D Bosch. 2010, Assessment of different representations of spatial variability on SWAT model performance, Trans. ASAE., 53(5), 1433-1443.

Bekele, E. G., and J. W. Nicklow 2005, Multiobjective management of ecosystem services by integrative watershed modeling and evolutionary algorithms, Water Resour. Res., 41, W10406, doi:10.1029/2005WR004090.

Brechbill S C, and W. E. Tyner 2008, The economics of renewable energy: corn stover and switchgrass, BioEnergy: Fueling America Through Renewable Resources, Purdue Extension, ID-404-W.

Chatterjee, A. 1997, Watershed optimization of BMP implementation schemes using genetic algorithms, M. S. thesis, Pa. State Univ., University Park.

Cibin, R., Chaubey, I. and Engel, B. 2012, Simulated watershed scale impacts of corn stover removal for biofuel on hydrology and water quality. Hydrol. Process., 26: 1629-1641. doi: 10.1002/hyp.8280

Cibin, R. 2013, Optimal Land Use Planning on Selection and Placement of Energy Crops for Sustainable Biofuel Production. PhD dissertation, Department of Agricultural and Biological Engineering, Purdue University, ProQuest, UMI Dissertations Publishing.

Deb K, A Pratap, S. Agarwal, and T. Meyarivan 2002, A fast and elitist multiobjective genetic algorithm: NSGA-II, IEEE Trans. Evol. Comp., 6(2): 182-197.

Deb, K. 2001, Multi-Objective Optimization Using Evolutionary Algorithms, John Wiley, Hoboken, N. J.

Engel B, D. Storm, M. White, J. Arnold, and M. Arabi 2007, A hydrologic/water quality model application protocol, J. Am. Water Resour. Assoc., 43(5):1223-1236.

Gitau, M.W., T. L. Veith, and W. J. Gburek 2004, Farm-level optimization of BMP placement for cost-effective pollution reduction, Trans. ASAE., 47(6), 19231931. 
Goldberg, D. E. 1989, Genetic Algorithms in Search, Optimization and Machine Learning, Addison-Wesley, Boston, Mass.

Haario H., E. Saksman, J. Tamminen 2001, An adaptive metropolis algorithm, Bernoulli 7(2): 223-242.

Holland, J. 1975, Adaptation in Natural and Artificial Systems, vol. 20, Univ. of Mich. Press, Ann Arbor.

Hu, X., R. C. Eberhart, and Y. Shi 2003, Particle swarm with extended memory for multiobjective optimization, Proceedings of the IEEE Swarm Intelligence Symposium 2003 (SIS 2003), Indianapolis, Indiana, USA. pp. 193-197.

Joseph J.F., and J.H.A. Guillaume 2013, Using a parallelized MCMC algorithm in R to identify appropriate likelihood functions for SWAT, Environmental Modelling \& Software, 46: 292-298, http://dx.doi.org/10.1016/j.envsoft.2013.03.012.

Kalcic, M.M., J. Frankenberger, L. Prokopy, and I. Chaubey. 2014. An in-depth examination of farmer perception of targeting conservation practices. Environmental Management. Doi: 10.1007/s00267-014-0342-7.

Kennedy J, and R C. Eberhart 2001, Swarm Intelligence. Morgan Kaufmann: San Mateo.

Kennedy, J. and R. C. Eberhart 1995, Particle swarm optimization, Proceedings of IEEE International Conference on Neural Networks, Piscataway, NJ. pp. 1942-1948,

Lautenbach, S., M. Volk, M. Strauch, G.Whittaker and R. Seppelt 2013, Optimizationbased trade-off analysis of biodiesel crop production for managing an agricultural catchment, Environmental Modelling and Software 48: 98-112.

Maringanti, C., I. Chaubey, and J. Popp 2009, Development of a multiobjective optimization tool for the selection and placement of best management practices for nonpoint source pollution control, Water Resour. Res., 45, W06406, doi:10.1029/2008WR007094.

Maringanti, C., I. Chaubey, M. Arabi, and B. Engel 2011, Application of a multiobjective optimization method to provide least cost alternatives for NPS pollution control. Environ. Manage., DOI: 10.1007/s00267-011-9696-2

Neitsch S L, Arnold J G, Kiniry J R, Williams J R. 2011. Soil and Water Assessment Tool Theoretical Documentation, version 2009, Temple, TX. USDA Agricultural Research Service and Texas A\&M Blackland Research Center.

Rouholahnejad E., K.C. Abbaspour, M. Vejdani, R. Srinivasan, R. Schulin, A. Lehman 2012, A parallelization framework for calibration of hydrological models Environmental Modelling and Software, 31: 28-36. 
Runkel R L, C G Crawford, and T A Cohn 2004, Load estimator (LOADEST)-A FORTRAN program for estimating constituent loads in streams and rivers: US Geological Survey Techniques and Methods, Chapter A5.

Sreekanth, J., and B. Datta 2011, Coupled simulation-optimization model for coastal aquifer management using genetic programming-based ensemble surrogate models and multiple-realization optimization, Water Resour. Res., 47, W04516, doi:10.1029/2010WR009683.

Srivastava, P., J. M. Hamlett, P. D. Robillard, and R. L. Day 2002, Watershed optimization of best management practices using AnnAGNPS and a genetic algorithm, Water Resour. Res., 38(3), 1021, doi:10.1029/2001WR000365.

Storn R, and K. Price 1997, Differential evolution - a simple and efficient heuristic for global optimization over continuous spaces, J. of Global Optimization, 11: 341359.

Sudheer, K.P., G. Lakshmi, and I. Chaubey. 2011. Application of a pseudo-simulator to evaluate thesensitivity of parameters in complex watershed models.

Environmental Modelling and Software 26: 135-143.

Veith, T. L., M. L. Wolfe, and C. D. Heatwole 2003, Optimization procedure for cost effective BMP placement at a watershed scale, J. Am. Water Resour. Assoc., 39(6), 1331- 1343, doi:10.1111/j.1752-1688.2003.tb04421.x.

Vrugt JA, and B A. Robinson 2007, Improved evolutionary optimization from genetically adaptive multimethod search, Proc. Nat. Acad. of Sciences, 104: 708-711.

Williams, J. R. 1975, Sediment Routing for Agricultural Watersheds. J. Am. Water Resour. Assoc. 11(5): 965-974.

Wu Y., T. Li, L. Sun, J. Chen 2013, Parallelization of a hydrological model using the message passing interface, Environmental Modelling and Software 43: 124-132

Yalew S., A. van Griensven, N. Ray, L. Kokoszkiewicz, and G.D. Betrie 2013, Distributed computation of large scale SWAT models on the Grid, Environmental Modelling and Software, 41: 223-230, http://dx.doi.org/10.1016/j.envsoft.2012.08.002.

Zhang X., P. Beeson, R. Link, D. Manowitz, R. C. Izaurralde, A. Sadeghi, A. M. Thomson, R. Sahajpal, R. Srinivasan, and J. G. Arnold 2013, Efficient multiobjective calibration of a computationally intensive hydrologic model with parallel computing software in Python, Environmental Modelling and Software 46: $208-218$ 
Zhang, X., R.Srinivasan, and M. V. Liew, 2010, On the use of multi-algorithm, genetically adaptive multi-objective method for multi-site calibration of the SWAT model. Hydrol. Process., 24: 955-969. doi: 10.1002/hyp.7528

Zitzler E, and L. Thiele 1999, Multiobjective evolutionary algorithms: a comparative case study and the Strength Pareto approach, IEEE Trans. on Evol. Comp., 3(4): 257271. 